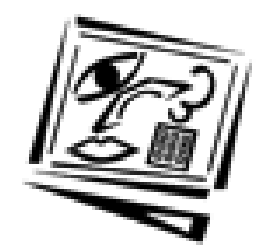

\title{
The role of synchronous communication in fully distance education
}

\author{
Gary Motteram \\ The University of Manchester
}

\begin{abstract}
The issue of whether distance education can fulfil the needs of learners has been much discussed in the literature. It is generally felt that there are two key facets to an educational context which are vital to the process of education, one is the building of a community within a group and a second is the deep understanding of ideas and issues that are presented as part of a course. This paper shows how both these aspects of learning can be facilitated through a number of different online tools in the context of fully distance Masters education. It argues further that synchronous tools are more effective for the 'social' side of education and that asynchronous tools are better at dealing with the 'academic' aspects of the course.
\end{abstract}

\section{Introduction}

The Language and Literacy Group (formerly the Centre for English Language Studies in Education) at the University of Manchester has been involved in distance education since 1988. Since 1996, it has offered an MEd in Educational Technology and English Language Teaching (MEd Ed Tech \& ELT) fully distance, ie students are no longer required to come to Manchester to follow any part of their course of study with us, but are supported at a distance using a variety of technologies, including computer mediated communication (CMC).

Some of the reasons why it was decided that the Group should move away from full time, on site education are explained by one of our students who describes her needs and experiences:

Quotation 1 (Q1): With regards to my experience of Distance Learning the bulk of it has been with this masters programme. (I'm on the full distance programme.) I've found it fits in perfectly with my life style - I can study when I find the time (usually quite late at night). It's also helped me economically as I could not afford to take a year off work to study (though I would love to!) In a way I think studying and working at the same time has been profitable as I have been able to try out many of the things I've read about and in that way develop my ideas more. 
This description clearly outlines key issues for students on courses like those at Manchester and in other similar institutions. The description shows the desire for study, but the constraints, too. Without the fully distance programme there might be little chance of this student achieving her ambition. It shows when course work gets done, and this is not untypical of distance education generally. It also shows how important it is for in service teacher education that a student remains in contact with their own teaching contexts, as they are able to try things out directly to see how successful new ideas are in their particular contexts. This has been termed situated learning by Mason (1998).

There has been considerable discussion in education circles in the UK about the continuing role of educational research, and it has become clear that key voices in this debate (Elliot, 1999, Hammersley, 1997 and Hargreaves, 1996 \& 1997) believe (for different reasons) that more research should be undertaken by practising teachers. The kind of course offered at Manchester enables practising teachers to do research in their own contexts (these teachers are based in countries all over the world), but gives them the necessary support from tutors and access to the literature that they need to make sure that the work they do is informed by ideas.

The course consists of six taught modules and a dissertation. Early modules are taught using more a traditional style of distance material, principally paper, but often now accompanied with audio, video, and / or computer based learning packages. All of the specialist educational technology modules are supported using email and so course participants are kept in regular contact with the course coordinators and tutors.

The module that is the focus of this discussion, Computers and Video as a Resource for the Language Teacher (CVR - now called Computers, Language and Context, following revisions), is taught online with a small print introduction and a CD-based tutorial which is used to exemplify multimedia in language teacher education. The module makes use of web pages and a number of interactive communication tools. All of these help to provide the learning experience and illustrate to the learners what can be done with what technology. See below for further details.

\section{Computer mediated communication}

There is continuing debate in the world of education about the roles that CMC can usefully play in supporting learning. This debate is related to a strongly held view that without physical meetings, it is not possible to establish an effective community of learners and as a result learning will be impoverished. Many people would still argue this in these days of effective Internet communications and most distance courses still place 
great store in the physical tutorial support that is offered. There are also potentially cultural differences here that have been highlighted by Keegan (1986). A broad distinction is made by Keegan in which he talks about societies that are more individualistic and independent and those that are more group focussed and reliant on the teacher. The suggestion is that the more individualistic learners are more likely to be better equipped for online learning.

The discussion about effective online learning of course assumes that traditional face to face education is a positive experience and is a model that distance / online education has to live up to, however, Laurillard (1993), in her influential book, points out that this may be a fallacy. A recent study by Hoey et al (1998) undertaken at North Carolina State University has also shown that there is no significant difference between face to face and online education in terms of achievement. However, it does seem the case that in many reports of online courses that a physical group existing before the start of the course can be effective. Davis and Holt (1998), for example, come to this conclusion following an experiment in CMC which went rather badly wrong. They had attempted to run an online discussion making use of "critical incident reports", but had not anticipated the resistance to participation:

The false assumption that was made about this experience was that this group would be easier to facilitate than any other, that it would be driven by notions of international goodwill and technological ease. (Davis and Holt, 1998: 326).

They experienced strong resistance to participation and felt that this might have been overcome if they had met as a group in advance.

Feenburg (1989:22) argues that the need for education to include a face to face element is strongly embedded in western culture, he says that: "In our culture the face to face encounter is the ideal paradigm of the meetings of minds". He further suggests that oral discussion is perceived as more important than textual. This he argues comes from the Platonic tradition where debate was given more importance than text.

Feenburg's view was expressed over ten years ago at a time when there had already been quite a lot of work undertaken in computer mediated discussion environments and there was an established view of what constituted good CMC practice (see below).

However, in the later literature that discusses CMC and its value, there is a conflicting view of these issues. Garrison argues that CMC is so successful precisely because of its written nature. It may be a kind of writing all of its own, as Colette Daiute (1985) once described it as "talky writing", but it is writing after all. 
Garrison (1997: 4) argues:

"... the reflective and precise nature of written communication is very

different from the spontaneous and less structured nature of oral discourse in either a face to face, video, or audio teleconferenced context."

It is much easier to go back over messages that have been presented in a computer conference and review them. All of the detail is there. Later in his article, Feenburg (1989) also tends to support this view: "A group which exists through an exchange of written texts has the peculiar ability to recall and inspect its entire past" (p25). It may find it easier to rework the ideas that are being presented, to handle the information in a more complex way because there is time to reflect on the issues. At the end of an online debate we can end up with a collection of ideas that build one upon another to provide a deeper analysis.

Another hotly debated issue, which is relevant to the way that online learning happens, is the changing role of the teacher in classrooms in general. In the discipline of English Language Teaching, the view the teacher expressed below is a familiar one (see for example Harmer, 1983).

"Unlike traditional classroom activity, in which the teacher directs instruction, leads the lesson, prompts responses, and paces the class, online group learning is student centred and requires a different role of the teacher, of facilitator rather than lecturer. The teacher plans the activities but then follows the flow of the conversation, offering guidance as needed rather than strictly adhering to the preplanned agenda or syllabus."

This quotation from Harasim et al (1995: 174) seems to be emphasising the flexibility of such interactions, also their conversational nature, suggesting an important role for such language.

The contention of this paper would be that in order to be successful with fully distance online education, for it to be accepted by sceptics who would suggest that only classroom based learning is effective, CMC needs to play a number of different roles in the learning environment. It appears to need both a spoken element and a written element. Some of the questions that need to be answered include:

- What function should these elements play?

- Should it be like face to face education with input, discussion, reading, discussion, assignment, feedback, all part of an iterative process, or something different?

- Does the nature of online learning change this paradigm, does it add to it?

This article attempts to begin the process of answering these questions, by looking at specific examples of data from the module in question. 
Part of the answer might come from Berge who, according to Wisenberg:

... offers an instructional framework that categorises 'teaching' in a virtual classroom as a 'moderating' function that has four critical components: pedagogical (didactic and guidance oriented), social (supportive and consultative), managerial (administrative and organizational), and technical (technical skills building and troubleshooting).

The two aspects of this framework, the pedagogic and the social, that are relevant to the data presented in this paper will be used to describe how the different kinds of interaction appear in this course work and what impact they have.

\section{The computers and video as a resource module}

The module that is being discussed here is currently the only fully online module that is taught, although email and web page support is provided throughout the MEd in ELT programme. The module generally comes towards the end of a participant's time on the programme and is open to any course member whether they are following the fully distance MEd, or not. At the time of writing, it is in its third year of running as a distance module, but has been taught on site since 1989. Its content now focuses on the impact that the Internet and online learning and are having on the ELT profession and explores a number of topics: CMC itself, distance education, teacher education, research and computer based testing.

Although CMC is not a new idea, access to it before the advent of the Web was quite limited. In the past three years the number of tools that has become available has grown significantly, many of them are free. Even assuming you wanted to, selecting one to suit a diverse set of academics at a University the size of Manchester is difficult. Many online groups, however, do make use of commercial conferencing packages like First Class (favoured by the Open University in the UK), Lotus Notes, or Web CT (a package used elsewhere at Manchester and soon to be available to all the academics). These tools can be expensive for institutions to buy and also for the course participants to use online. They have many similar properties. As this is a course about educational technology as well as about ELT, it is important for the participants to get a good idea of as wide a variety of packages as possible, it is important to use a number of different types of software. Email is used as a baseline communications tool, because it is now very familiar to the majority of teachers who take courses at Manchester. It is cheap and reliable and the course shows how the addition of distribution lists and archiving make it even more useful.

The module under discussion uses the following Internet technologies, which have varied from year to year as ideas have changed about how 
best to run the module and also the access that the students have had to these technologies:

- Email and distribution list which is archived and can either be viewed as threaded, or in date order.

- Web pages - currently only text, but will soon have audio and video clips as part of the site.

- A bulletin board (facilitate.com) which can also be used synchronously (but not so far successfully by us)

- Synchronous discussion: Parachat

\section{MOOs}

MSN Messenger

Audio/video conferencing

These technologies have also been chosen because they illustrate for the participants on the module different aspects of the online world in the educational technology and ELT discipline. The module starts with email and the web, because the participants are usually familiar with these tools and then moves on to using the technologies they are less familiar with eg IRC, or MOOs. Reasons for doing the course in this way are discussed in more detail in Motteram (forthcoming)

Of course, these technologies need to be used effectively in order to give students the best chance of maximising their learning from the module. Harasim et al (1995: 191-2) have provided online moderators with clear guidelines on how they see best practice in an online world. It is as follows:

The key concept in network teaching is to facilitate collaborative learning, not to deliver a course in a fixed and rigid, one way format.

- Do not lecture. An elaborate, logically coherent but long sequence of comments often produces silence. Use short comments that are open ended and invite response.

- Be clear about expectations of the participants - for the course as a whole and for each module, assignment, or time period within it.

- Be flexible and patient. Guide the conversation, but do not dominate it.

- Be responsive. Especially at the beginning of an online course or activity, ensure that every comment is responded to. If no one else replies, respond by messaging or by mentioning the author's comment.

- Do not overload. Contribute no more than one long comment a day, or less if the students are actively contributing. Several short notes are more likely to be read and appreciated than a single long entry. 
- Monitor and prompt for participation. Read the status report offered by the system frequently. Send private messages to those who are falling behind or are reading but not writing. If they have not signed on for a week or more and do not reply to these messages, call them on the telephone and help them with their problems or suggest ways in which they might contribute.

- For assignments, set up small groups and assign tasks to them. If the class is too large to have a single discussion space without overloading participants, divide it into two or more discussion groups.

- Be a process facilitator. Make sure that participants understand and abide by good netiquette by not insulting each other or getting far off the course topic.

- Encourage meta-communication about the process, and make suggestions for improving the experience for all the participants.

- Write weaving comments every week or two, or assign individuals to groups of students to take on this task of summarizing and focussing the discussion.

- Organize the interaction. Electronic housekeeping includes moving or deleting items that do not belong in a particular conference and organizing and modelling the use of key words and explicit references and associations among items to show relationships.

- Set rules and standards for good netiquette, and encourage metacommunication about anything that is causing the experience to be less valuable or enjoyable for all than it might be.

- Establish clear norms for participation and procedures for grading online work that give credit for good participation.

- Assign individuals or small groups to play the role of teacher and of moderator for portions of the course.

- Close and purge moribund conferences in stages, giving members an opportunity to save whatever messages they wish to keep.

- Adopt a flexible approach toward curriculum integration on global networks. Curriculum areas will be affected by the diversity of opinions from different locations in the world. The best approach is to be open to changes and accept new views on various topics." (pp 191-192)

Although this is a useful list, it still has some problems. There still appears to be a conflict between what Garrison is saying and the advice given in the Harasim et al list. There is an emphasis in this list on keeping the discussion going, on short inputs, not in encouraging more detailed interactions.

For the type of course that is being offered at Masters level, it is important to go beyond surface discussion of issues. The kind of approach that is characterised by Toohey (1999: 9) as a "deep approach" is the one that is favoured. In this approach students are said to be more concerned with getting a thorough knowledge of the subject, than in getting high marks. 
This type of learner is contrasted with "surface learners" who have a more instrumental approach to the education process. Garrison appears to be arguing for something similar, he suggests that by using writing based $\mathrm{CMC}$ we can construct new knowledge and this is the goal on our course.

During the first year that this module was run online, a participant who had asked to audit the module kept a diary of her experiences. When she was interviewed later about what she had written, she talked about the fact that she felt that most of her learning on the course in general had occurred when she wrote the assignments and this view accords well with Garrison and others, as this student had recognised that by writing down her ideas she was potentially developing new knowledge from them which would be useful for her beyond the end of the course.

\section{The research}

Edge and Richards (1998) make a cogent case for the kind of ethnographic research described in this article. Here we are seeking "authority with" (p341) the participants in the course by speaking with their voices along with our own reflections on what is being said. The data that has been collected is read through and coded in order to find patterns and ideas which either support, or contradict prevailing ideas on the role of CMC in such Masters level courses.

Jones (1998: 32) talks about how such research can be presented to make it speak to a wider audience, he says:

The basis for judgement in an ethnography can be summed up in terms of credibility and plausibility. By credibility, I mean a claim that one could reasonably expect the transcription of the conference and field notes to be accurate. These materials are continuously available as checks on accuracy. By plausibility, I mean persuasiveness that the accounts given would make sense to a member of the conference or another observer, even if they were disputed... The research further needs to show its relevance, and that requires consideration of both the problem addressed and the audience it is directed to.

It is our intention that the data that is presented in the following pages, although edited, will make you confident that the ideas presented here are credible and that the interpretation is plausible. Data has not needed to be transcribed, because it comes in a digital form.

In order to provide a basic framework in which to analyse the data, two of Berge's functions: social and pedagogic will be referred to throughout the analysis. These two functions are helpful in understanding what is happening and the best use that can be made of the technology. Reference to the Harasim et al guidelines on successful CMC will also be made. 


\section{The data and the participants}

The data comes from two different groups of learners and consists of messages taken from a discussion list and logs of synchronous discussions. The first group who took the module fully distance in 1998 consisted of 8 participants, one of whom was observing / auditing. The second group started the module at the beginning of 1999 and have all now successfully completed it. There were 14 in this group with two auditors / observers. The extracts from the messages mainly come from email, and reflect how the participants are thinking about their experiences, but there is also data from the log of a MOO and from Parachat.Com. The participants are based in a number of different countries and varied considerably in their experience of $\mathrm{CMC}$. At the beginning of the module, few had made any significant use of anything but email.

\section{Social functions of CMC}

In the data there are several reflections on the social dimension of the different methods of communication.

The following quotation (Q2) shows the strong desire this person had to get to know people in the group better. A natural reaction, perhaps, and indeed she felt more part of the group as a result of the online chat, short as it was for her. In fact, she had a real struggle to get to the meeting and almost failed in the end to make it, however, her feelings were still quite positive at the end of her encounter.

Q2: And hey presto! I had not read my mail properly and you were in the members chat area! I was so annoyed with myself! (How many times do I tell my students to read things carefully before acting? Maybe I should listen to my own advice!!)

So, I joined up, with the nickname of A. Entered and connected. Finally! It was such a great feeling to finally get there and see people I recognised who were actually chatting! By this time it was 3.40 and people were just leaving but even so I felt really great! I'm now looking forward to chatting more next week.

My brief experience of chatting like this was great. It just took a few minutes to get used to following the various threads of the conversation.

This seems to describe the strong social need that is a clear element in the face to face experience of education and is being replicated here in the online environment. People feel securer in giving out their own ideas when they know the other participants better. A lot of time is spent in our on site version of this course in getting students to work together. 
Another student could not get to the online discussion at all in the early stages of the module. Her reflections on this experience are below:

Q3 After a little while still blocked I went to e-mail intending to signal what was going on for me. Found J's first messages. Wished I'd thought of e-mail earlier. Went to Parachat as she suggested. Had looked at Parachat during the previous week, along with SchMOOze. Remembered seeing something about 2 possible entry points, Java enabled/non-Java enabled. Arriving at Parachat, I realised I didn't know where J was - which room? Back to almost synchronous e-mail to check. Back at Parachat; no chat for me as no Java enabled browser (it's schMOOze which offers two entry points). This is one hour after hitting Facilitate.com. Feelings during the hour: frustration, confusion, stress, disappointment. Learning curve: realisation of the importance of signals and signposts. Not to mention the right technology. It's a jungle out there! And fallback plans in place - if something doesn't work, try this. And knowing there's a place to go if all else fails (in this case, e-mail). Lack of Java-enabled browser; how much of a handicap is it for this module?

Some of the tools we try out on the module are used experimentally and as a result don't always work. This can easily lead to frustration. Frustration is very evident in Q3. However, the participant has taken the experience and transformed it to use these experiences to inform her practice for the future. This is what Schön, in his influential work, has called "reflection in action" (1991) and Toohey (1999) describes as "deep learning". As part of the work that she did for her assignment, this particular student went on to do a similar activity with a group of her own students and applied what she had learned very effectively.

Another participant who met quite successfully in the group environment showed this same sense of need for the equivalent of the physical 'classroom':

Q4 I felt as if that large weight of not being in a classroom atmosphere throughout this course was lifted from my shoulders. It was nice to 'meet' my classmates, albeit virtually ... It was like I was actually there!! (with humorous tone)

Another participant refers to the first meeting as an "ice breaker". This reference to "ice breaker" resonates with ELT teachers. A lot of time is spent on the affective in ELT, and quite rightly a good deal of time is spent on this in teacher education, too. In order for our students to reflect effectively on their past teaching experiences, they have to feel comfortable with the other course participants. Being comfortable with others and with themselves helps people to become more receptive to new ideas. Here it is in $\mathrm{CMC}$ and it clearly has the same function of helping to establish a feeling of community with others on the module. Another quotation 
confirms this and also makes a link to the participant's interests in trying out things in their own classes:

Q5 All in all, however, I have to say that I was thrilled with the conferencing. I would love to try it with my students... It's definitely something I look forward to doing again.

Here we have clear indications of the group forming, of people coming together to create the community that is going to be this particular module. We appear in this year to have gone straight to norming and performing phases (Tuckman, 1965) where the participants have settled down to do the activities that they have been assigned.

There appears to be initial evidence here that the CMC environment can provide at least some of the community that the participants are looking for. The exact role that this played will be investigated in more detail when more of the data has been analysed.

What is interesting is that this social function is not met as easily by the exchange of email messages and archiving, it is the immediacy of the synchronous activity that provides that socialising function.

\section{Learning online}

This section will explore how the synchronous activity fails to provide deep learning, but that the subsequent reflection in asynchronous mode helps to focus the participants and enables them to come to a deeper understanding of the ideas that are being discussed. Several of the participants talk about how difficult they find it to keep up and contribute in the synchronous sessions:

Q6 I found it fast, sometimes too fast! I could not always keep up with the flow of the discussion.

Q7 I found myself wanting to respond to everything immediately, but my typing challenged self hindered that.

There are also comments about the nature of the communication in a synchronous environment:

Q8 I also found that our communication was very brief (it seemed like 3-5 words per message) ... One other point of interest for me was the feeling the need to think five times about what my comments were going to be. I felt very insecure in knowing that my comments were going to be in writing and permanently on record, as opposed to being spoken and normally forgotten after a short time. I wanted everything I said or asked to be perfect, or even profound. 
This shows a good understanding on the part of the participant of one of the key distinctions between written and spoken language, that of permanency and mentioned earlier in this article. It also highlights the contradiction for me between the need to say "profound" things and the nature of an environment that encourages short turns. MOOs, synchronous chat with Facilitate.Com, or Parachat tend to consist of quite short turns because of the nature of the environment.

Parachat transcript

$>$ [t] From tonight's experience, I think

$>$ - we should meet here at Para, as for timing...

$>[t]$ Has anyone set up a conference?

$>$ s1> No

$>$ [s2] INo

$>$ [s3] No. But I agree with meeting here,

$>$ - unless there's a better place. Let me know

$>$ - when.

$>$ s1 > Ditto - though I'm not on the

$>$ - Wednesday list

$>$ [s2] Neither am I can I join?

This is equally true of a MOO ("You" indicates the tutor's contribution):

MOO Log

You say, "I have seen some listening test materials using video designed by Glenn Fulcher at Surrey - it looked good to me but there were technological problems - such as requiring lots of memory"

M says, "yes it is still a little cumbersome - I have a dislike of scrolling, so I'd like to suggest that that is reduced"

Owl [to J [Guest]]: That's what I thought

You say, "dialang uses a lot of scrolling and i agree that it is a strain on the reader - especially when the stress of the test situation is considered"

Owl says, "I didn't manage to find any dialang tests - only a description of the scheme"

You exclaim, "yes- unfortunately we are still writing them!"

You say, "interestingly there is a lot of debate going on about the testing issues of dialang (not the technology) - issues such as construct validity and subtlety of feedback are two of the main areas of disagreement"

You say, "this is why the whole project is behind schedule"

An extended turn needs to be broken up into smaller parts, so that it does not develop into a lecture, although in this example it has become more like one. One of the disadvantages of these tools is generally that you do 
not see the contribution of participants until they are committed to the screen by pressing the Enter key, for example, so the other participants will be waiting for a contribution, unless it is broken up. Work can be preprepared, but then does start to become one way transmission rather than a discussion. One of the few positive features of Facilitate.Com (if the administrator allows this to be the case) is that anyone can edit the material after it is posted. This can be seen both positively and negatively, of course, but allows the participants to edit their way out of an unhappy posting, in the same way that you can retract something that has been spoken.

So far then we have seen that although academic discussion is possible in the synchronous environment, ideas do not appear to have been developed in depth. It may be as a result of the management of the activity , but equally it may be the nature of spoken interaction in an academic environment, which allows rehearsal of ideas, but does not allow deep study.

Let us turn to the "deep" side of the course now and how this is achieved After an online group activity, either one of the group is asked to summarise the main issues that came up in their discussions, or this is done by the tutors. Logs of the $M O O$ and Parachat, for those that could not make the online discussions, are posted on the discussion lists.

Group activities that are independent of the tutors are also encouraged. This group activity is usually done using the same environments. In the first year we did two such group activities and had initial problems because of time differences and grouping:

- one of the groups did not work well together during the first activity;

- the initial groupings for the second activity did not work and the students themselves suggested a regrouping. Initial groups were based on the tutor's perceptions about knowledge of topic and did not take account of the social dimension in that sub groups had already formed as a part of the online interaction.

However, once these initial difficulties were sorted out the activities most of the group worked well together and completed the tasks.

What follows is an extract from a much longer email message (about 500 words in total) to the core discussion list. This is a summary of paired discussion about topics raised by the tutors. It talks both about the role of MOOs and email in distance education. This extract has been picked because it focuses on some of the key issues in this paper. 
Q9 SPEAKING vs TEXT

X's comments that a MOO was more like speech than an email is a valid point. However, context is an important feature for both. For instance, our MOO sessions have mostly been speech except for the last one related to the CMC module. This was an exception because we had already been prepared for the context by Gary's message. This made the session a much more focussed one compared to the general chat or answers to specific question than before. How people contribute to the MOO session is another question. How do you control turn-taking or stopping people from dominating the session? How do you encourage less vocal or slower thinking participants to contribute? In these cases email may be the better option. As for the implications for our work as language teachers, I think control of context is important in order to achieve the desired result. Also setting up the task is important. Again, the example of our MOO sessions is a case in point. How much more useful could our sessions had been with a little more forward planning? If you compare email tutorial support with that of postal support, email support is much quicker. Problems can be solved faster with email and you can develop a dialogue with tutors. Both MOOs and email are possibilities for students and tutors to get to know each other better. For solving technical problems e.g. with the CALL project email was not very effective because of the distance aspect. Questions asked could have been solved more easily by being in the same room as the tutors. Quite often explanations given were not easily understandable and so could be ignored. It was often embarrassing to ask basic questions but the fact that questions were asked and answered 'publicly' gave an indication of how other students were coping. This informed everyone on the range of ability and experience in developing CALL applications - a positive experience in itself (most of the time). Email is less technically problematic than MOOs, but MOOs are more satisfying (when they work) due to their immediacy.

The participants have put some effort into their discussion and some interesting issues have been raised. The debate here is at a deeper level than that in the earlier synchronous examples. The students have gone beyond surface discussion the issues and are looking quite critically at the issues involved.

The MOO environment was not originally conceived as being somewhere for "focussed discussion". The suggestion for using the MOO came from a few members of the first group itself quite early on in the course and it was a place where they met on their own and then started inviting the tutors to join in. For the tutors, the key communications technologies were to have been the distribution list and private email. MOO was only ever seen as social environment with opportunities to deal with questions quickly and efficiently, it was possible in the MOO to get closer to the idea of "being in the same room as the tutors."

As the course progressed over the first three years and the CVR module came around (for many of the first year group this was their last taught 
module), the desire to have more formal discussions at the MOO became more evident, this ideas was responded as is evidenced a shorter extract from Q9:

X's comments that a MOO was more like speech than an email is a valid point. However, context is an important feature for both. For instance, our MOO sessions have mostly been speech except for the last one related to the CMC module. This was an exception because we had already been prepared for the context by Gary's message. This made the session a much more focussed one compared to the general chat or answers to specific question than before.

This shows the way that a facilitator can respond to the expressed needs of the students. Although this quotation is about the MOO, the actual comment is presented via email, again showing how the email environment is used to build up argument.

This message exposes the tension between a need for social contact on a course and the need to get on with the academic side. This kind of tension exists in all types of education because in most cases course participants feel that they have limited time to get access to tutors to get the information they want. However, the courses that are run at Manchester are not designed to present knowledge as product, the aim is to aid the participants to come to a better understanding of their own ideas, to engage with the ideas of others, both those of other participants and the key writers in the field, to facilitate the development of knowledge. This facilitating function is one that is seen as crucial in CMC as has been said.

Let us now consider the knowledge growth of the course participants here through the evidence of the messages. Q8 (see earlier) talks of the participant's need "to think five times about what my comments were going to be." Another quotation shows the depth of commitment of one of the participants, but also the constraints of adult learning:

Q9 This module is the most time-consuming yet stimulating I've taken. Unfortunately some nights I'm worn out by putting the baby to bed., let alone the day's events, so that I can't sit down and type for an hour, and fill in my journal. I also want to respond to you cvr'ers but that would require a lot of cutting/pasting and re-reading of your mails, and would again take up time

This message also expresses the need to get deeper into the data that is being presented on the email archive. It shows a recognition of the importance of other participants' views.

This next quotation is a participant's "weaving" message (see Harasim et al list earlier). Here we see a synthesis of personal ideas supported with 
references to the literature. This participant mentions Warschauer (a well known ELT writer in this area) and there is another reference to "Mindweave" which is the book that Feenburg (1989) comes from.

Q10 Now that topic 1 is reaching an end it seems a good time to collect thoughts together. Along the lines of: Strengths and weaknesses of the CMC environment, with applications: A snapshot of feelings and reactions to events. Reading Warschauer I came across a phrase which summed up perfectly my feelings as I zapped from site to site during topic 1: like trying to get a drink of water from a gushing fire hydrant. So much information, so many more places to go, options to join lists, chat. Communicate or be damned!

Back to basics and some fundamental reorganisation of e-mail message files, downloaded articles ('mindweave' is a goldmine) and listing of promising addresses. Relief, it looks and feels more manageable.

E-mail discussion list: mine is up and running. A small group (4 doctors) and an initial time limit of 3 months with this distribution list and this purpose. They know each other and me (after 3 days' training together) so ice has already melted. I want to continue to use a non-directive approach and encourage self-directed learning and transpose it to a cmc environment. So call it a grammar discovery forum ('grammar' was their initial purpose together). Gotta start somewhere.

Using the experiential approach which we started with, they 'scan' medical or medically-related texts to observe how verbs and nouns behave (and whether the nouns have articles). That's a start.

Me on a list? The daily number of articles received is terrifyingly large (I'm away from my computer for days at a time sometimes). My experience of synchronous multi-user communication is largely theoretical - I've read about it. Have been to facilitate com. asynchronously, sometimes I've seen the whole flip chart sometimes I've just seen the last message posted. don't know why I can't access more. Destructuring traditional modes of communication - a playground - yes, I can see chat looks all that. Definitely feel a little destructured. Frequently wonder if I know what we're supposed to be doing and whether what I'm doing corresponds.

Had a reassuring message from fellow Mac user X. But still wonder when/how I'm going to get a Java-enabled browser and cannot understand why my Mac cannot decode simple text (the system blocks every time). A word of advice as a novice: don't try to chat (and stumble around systems) with the flu. I did - it's feverish already without the flu and misery with it.

That's it, I guess the strengths/ weaknesses is for the assignment. Next step for me is being an asynchronous facilitator with e-mail and setting up my own Web pages. Topic 2 comes just in time! 
This message gives a real insight into the developing ideas of our participant. It also shows that the recommended reading is having an impact on thought processes. There is the embryo of a possible assignment coming out of what is being done here, certainly a direct application of the module content to the participant's own students. Again, this message is delivered asynchronously, like the earlier more reflective one.

\section{Conclusions}

CMC then has at least two key functions in online education, it contributes to community, provides the social dimension to education that has been evidenced over the years by people gathering together in groups. Synchronous communication provides this more immediate social bonding, although in email it is possible, too. However, there is a tension for students in the time that they have to devote to their studies and the rest of their lives. Q1 and Q9 give an insight into the reasons for distance education and show us some of the pressures course participants put themselves under as learners, they also show the rewards. The messages show that you can form an effective group using electronic communication and provide the cohesiveness necessary to make it function as a group without physical meetings. At the same time you have potential to get beyond what is possible in face to face education because you have the written record of the interactions. It is possible to "weave" your way through the ideas, to reflect and review as is evidenced in Q10. Anyone can go back over the archived messages in detail, it provides a group record of the course as Feenberg argued. This complete body of information is where our knowledge about the topic can develop. The combination of input (via the Web and more traditional books and articles), the more social function of "chat", or more structured online seminars and the more thought developing reflective archived emails in combination with a summative assignment, enable the module participants to develop a deep view of the topics that they are studying.

This article has explored the relationship between synchronous and asynchronous communication in the context of fully distance teacher education. It has considered the role that each type of communication mode can play. Future studies need to explore further the role of deep learning in this kind of education environment and look closer at the relationship between on and off site learning. As we rapidly move down a path in higher education where more and more of our classes will be distributed, research into the most effective ways of conducting such learning will continue to help us to provide the most effective environments for our learners. 


\section{Bibliography}

Berge, Z. (1995). Facilitating computer conferencing: Recommendations from the field. Educational Technology, 35(1).

Daiute, C. (1985). Writing and computers. Reading, Massachusetts: Addison-Wesley.

Davis, M. and Holt, M. (1998). Having problems@cm.com: New ways to miss the point. Innovative Higher Education, 22(4).

Elliot, J. (1999). Evidence-based practice, action research and the professional development of teachers. Goldsmiths Journal of Education, 2(1).

Edge, J. and Richards, K. (1998). May I see your warrant, please? Justifying outcomes in qualitative research. Applied Linguistics, 19(3).

Feenberg, A. (1989). The written world: On the theory and practice of computer conferencing. In R. Mason \& A. Kaye (Eds), Mindweave: Communication, computers and distance education. 22-39. [verified 16 Aug 2001] http:/ / www-icdl.open.ac.uk/mindweave/ chap2.html

Garrison, R. (1997). Computer-conferencing: The post-industrial age of distance education. Open Learning, June.

Hammersley, M. (1997). Educational research and teaching: A response to David Hargreaves' TTA Lecture. British Educational Research Journal, 23(2).

Hargreaves, D. (1996). Teaching as a research-based profession: possibilities and prospects. Teacher Training Agency Annual Lecture, 1996.

Hargreaves, D. In defence of research for evidence-based teaching: A rejoinder to Martyn Hammersley. British Educational Research Journal, 23/4.

Jones, C. (1998). Evaluating a collaborative online learning environment. Active Learning, No 9. [verified 16 Aug 2001]

http:/ / www.ilt.ac.uk/public/cti/ ActiveLearning/al9pdf/jones.pdf

Harasim, L., Hiltz, S. R., Teles, L. and Turoff, M. (1995). Learning Networks: A Field Guide to Teaching and Learning Online. USA: MIT.

Hoey, J. J., Pettitt, J. M., Brawner, C. E. and Mull, S. P. (1998). Project 25 - First semester assessment - a report on the implementation of courses offered on the Internet as part of project 25 in the fall semester, 1997. http:/ / search.ncsu.edu or http: / / www2.ncsu.edu/vit/nsxflyer.jpg

Keegan, D. (1986). Foundations of Distance Education. London: Routledge.

Laurillard, D. (1993). Rethinking university teaching: A framework for the effective use of educational technology. London: Routledge.

Mason, R. (1998). Globalising education: Trends and applications. London and New York: Routledge. 
Mason, R. \& Kaye, A. (Eds) (1989). Mindweave: Communication, computers and distance education. Oxford: Pergamon Press. [verified 16 Aug 2001] http:/ / www-icdl.open.ac.uk/mindweave/mindweave.html

Motteram, G. (forthcoming). Internet technologies and their use in postgraduate English language teacher education. Presentation at the International Association of Teachers of English as a Foreign Language Special Interest Group Symposium in Gdansk, Poland September, 1998.

Schön, D. A. (1991). The reflective practitioner: How professionals think in action. Aldershot: Arena Books.

Toohey, S. (1999). Designing coursers for higher education. Buckingham: Society for Research into Higher Education and the Open University.

Tuckman, B. W. (1965). "Development sequences in small groups." Psychological Bulletin, 63, 384-399.

Wiesenberg, F. (1999). Teaching on-line: One instructor's evolving 'theory of practice'. Adult Basic Education, 9(3), 149-161.

Gary Motteram, Senior Lecturer in Education, Language and Literacy Group, School of Education, The University of Manchester, Oxford Road, Manchester M13 9PL, UK

Email: gary.motteram@man.ac.uk

Home Page: http:/ / www.man.ac.uk/langlit/ 